\title{
Atmospheric Pressure Ionization Permanent Magnet Fourier Transform Ion Cyclotron Resonance Mass Spectrometry
}

\author{
Andrey N. Vilkov, ${ }^{\text {a }}$ Chaminda M. Gamage, ${ }^{\text {a }}$ Alexander S. Misharin, ${ }^{\text {a }}$ \\ Vladimir M. Doroshenko, ${ }^{a}$ Dmitry A. Tolmachev, ${ }^{\mathrm{b}}$ Irina A. Tarasova, ${ }^{\mathrm{b}}$ \\ Oleg N. Kharybin, ${ }^{b}$ Konstantin P. Novoselov, ${ }^{b}$ \\ and Michael V. Gorshkov ${ }^{b}$ \\ a MassTech, Inc., Columbia, Maryland, USA \\ b Institute of Energy Problems of Chemical Physics, Moscow, Russia
}

\begin{abstract}
A new Fourier transform ion cyclotron resonance mass spectrometer based on a permanent magnet with an atmospheric pressure ionization source was designed and constructed. A mass resolving power (full-width-at-half-maximum) of up to 80,000 in the electron ionization mode and 25,000 in the electrospray mode was obtained. Also, a mass measurement accuracy at low-ppm level has been demonstrated for peptide mixtures in a mass range of up to $1200 \mathrm{~m} / \mathrm{z}$ in the isotopically resolved mass spectra. (J Am Soc Mass Spectrom 2007, 18, 1552-1558) (c) 2007 American Society for Mass Spectrometry
\end{abstract}

$\mathrm{F}$ ourier transform ion cyclotron resonance (FTICR) mass spectrometry is one of the most advanced analytical methods in modern chemistry and biology due to its unsurpassed mass measurement accuracy and resolution [1-3]. The majority of FT-ICR mass spectrometers are based on superconducting magnets with the field varying from 7 to 15 tesla that make them bulky, heavy, and costly. Nevertheless, there are many applications that do not require such high magnetic fields and can be effectively exploited at lower magnetic fields [4,5]. Permanent magnets that are relatively small, inexpensive, and easy to maintain compared with high-field superconducting magnets can be an attractive alternative choice for FT-ICR MS. The first attempts to build an FT-ICR mass spectrometer with a permanent magnet (PM) were significantly restricted by low magnetic fields and small ICR cell volumes [6,7]. The magnetic field in these instruments did not exceed 0.45 tesla. The results shown in these works indicated the potential of this approach and inspired further development. In recent years, significant progress has been made in the development of new magnetic materials with high levels of stored magnetic energy as well as in the improvement of numerical methods for the modeling of complicated magnetic assemblies. As a result of these improvements, PM-FTICR instruments with magnetic fields of more than 1 tesla have been built and tested. In 2002, Siemens Applied Automation (Bartlesville, OK) presented the

Address reprint requests to Dr. Andrey N. Vilkov, MassTech Inc., 6992 Columbia Gateway Drive, Columbia, MD 21046, USA. E-mail: andrey_vilkov@apmaldi.com first commercially available FT-ICR mass spectrometer ("Quantra") with a 1 tesla permanent magnet $[8,9]$. Another FT-ICR mass spectrometer with a 1.24 tesla permanent magnet of Halbach type named Mobile Ion Cyclotron Resonance Analyzer (MICRA) [10] has also been developed as a commercial product. Although these instruments show a reasonably good performance in terms of resolution, mass measurement accuracy, and sensitivity, their practical utility is critically limited to internal ion sources such as electron ionization (EI) or matrix-assisted laser desorption ionization (MALDI).

In this paper, we present for the first time an FT-ICR mass spectrometer based on a permanent magnet with an axial field that can utilize atmospheric pressure ionization methods. Two such instruments were built and independently tested at MassTech Inc., Columbia, $\mathrm{MD}$, and at the Institute for Energy Problems of Chemical Physics, Moscow, Russia.

\section{Experimental}

\section{Magnetic Field}

The FT-ICR mass spectrometer presented here comprises a novel yokeless permanent magnet of the reversible magnetic field (RMF) design illustrated in Figure 1 [11, 12]. The magnet is made from $\mathrm{NdFeB}$ material with an internal bore diameter of $42 \mathrm{~mm}$, weighs $37 \mathrm{~kg}$, and provides a 0.97 tesla axial magnetic field. Both the magnetic field magnitude and its homogeneity were measured using an axial Hall probe gaussmeter (Lake Shore Cryotronics, Westerville, $\mathrm{OH}$ ) that was mounted on an automated micrometer $x-y-z$ stage. The magnetic 

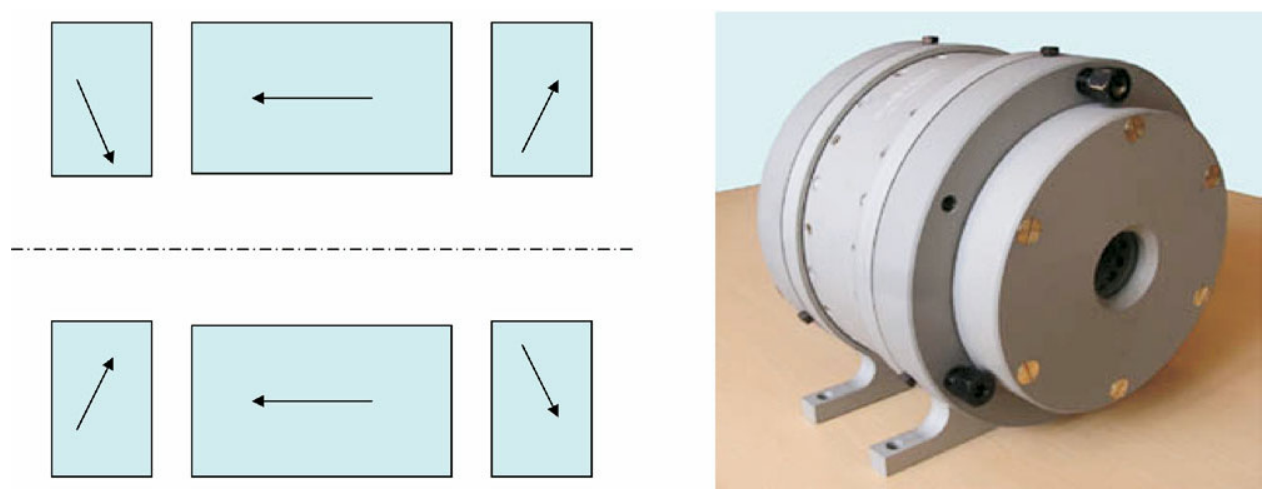

Figure 1. Schematic and a photograph of the 1 tesla permanent magnet. The arrows show the direction of magnetization of the ring magnet sections.

field inhomogeneity was found to be $500 \mathrm{ppm}$ over a central $1 \mathrm{~cm}^{3}$ volume of the magnet.

The temperature coefficient for $\mathrm{NdFeB}$ is $-0.2 \%$ per Celsius degree [13]. As a result, long-term drifts of the magnetic field are quite pronounced. Although thermal stabilization of the magnet was not utilized in this work, this feature will be definitely implemented in future.

\section{Vacuum System, Ion Optics, and ICR Cell}

The in-house built FT-ICR mass spectrometer shown in Figure $2^{\circ}$ Comprises $^{\circ}$ five $^{\circ}$ stages $^{\circ}$ of ${ }^{\circ}$ differential $^{\circ}$ pumping that gradually decrease the pressure from atmospheric to ultra-high vacuum in the FT-ICR cell region. A $2 \mathrm{kV}$ voltage was applied to the ESI needle to generate ions. The ions then entered a $0.3 \mathrm{~mm}$ i.d. stainless steel capillary (Small Parts Inc., Miami Lakes, FL) maintained at $120^{\circ} \mathrm{C}$ and biased at $+50 \mathrm{~V}$. The temperature of the heated capillary is controlled by a temperature controller (model CN9110A; Omega Engineering, Stamford, $\mathrm{CT}$ ). The first vacuum chamber was pumped to 1 torr by a $35 \mathrm{~m}^{3} / \mathrm{h}$ roughing pump (UNO 030M; Pfeiffer, Nashua, NH). The outlet of the heated capillary was inserted $2 \mathrm{~mm}$ deep into a $40 \mathrm{~mm}$ long quadrupole (inscribed radius of $2.616 \mathrm{~mm}, 6 \mathrm{~mm}$ rod o.d.) operated in the RF-only mode $\left(200 \mathrm{~V}_{p-p}\right.$ at $\left.800 \mathrm{kHz}\right)$ and DCbiased to $+10 \mathrm{~V}$ to confine and focus the diverging flow of ions exiting the heated capillary using the quadrupolar RF field. The first and the second vacuum stages were separated by a $1.5 \mathrm{~mm}$ i.d. conductance limit DC biased at $+4 \mathrm{~V}$.

The second, third, and fourth vacuum regions were separated by $1.5 \mathrm{~mm}$ i.d. conductance limits, pumped by a three-stage split-flow turbopump (TMH SplitFlow, Pfeiffer) with pumping speeds of 10, 250, and $262 \mathrm{~L} / \mathrm{s}$ for each stage, and evacuated to the pressures of $10^{-1}$, $10^{-4}$, and $10^{-7}$ torr, respectively. The last vacuum chamber containing an FT-ICR cell was pumped by a separate turbomolecular pump (TMU 262; Pfeiffer) with a pumping speed of $260 \mathrm{~L} / \mathrm{s}$.

In the second chamber, the ions were thermalized in a $80-\mathrm{mm}$-long collisional quadrupole (inscribed radius of $2.616 \mathrm{~mm}, 6-\mathrm{mm}$ rod o.d.) biased to $+3.8 \mathrm{~V} \mathrm{DC}$ and then transferred to a linear ion trap (LIT) through the second conductance limit.

The LIT assembly is used for ion accumulation, selection, and dissociation externally to the ICR cell.

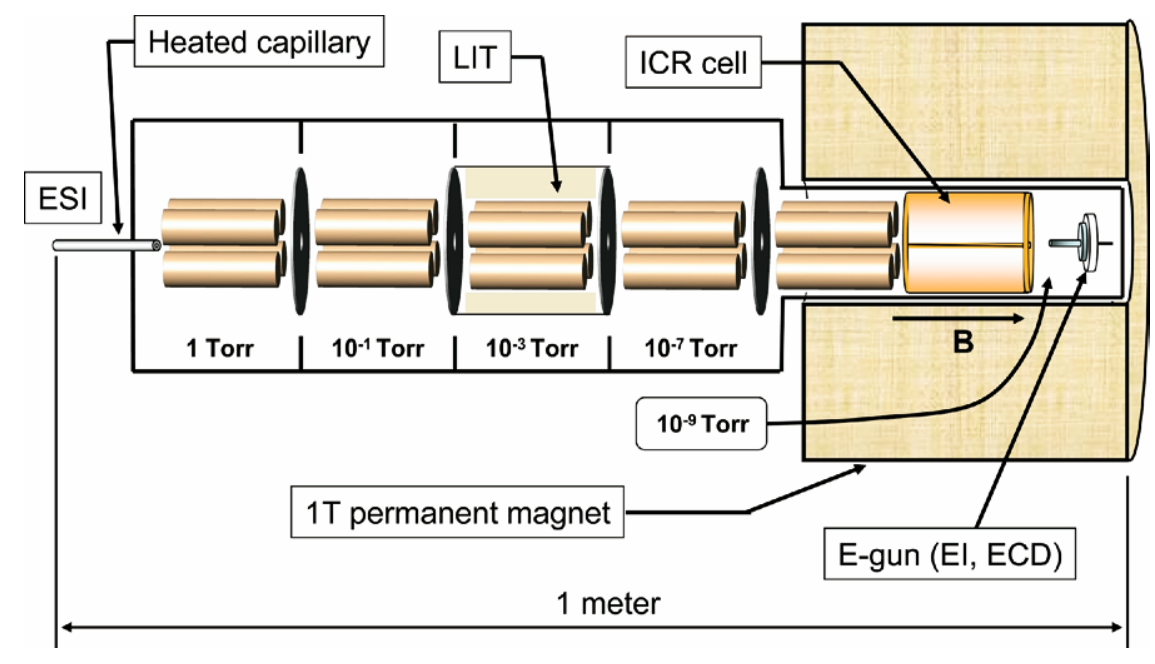

Figure 2. Schematic of the PM-FT-ICR mass spectrometer. 
The details and experimental data on ion selection and dissociation in the LIT of the PM-FT-ICR instrument are reported ${ }^{\circ}$ elsewhere $[14]$. In $^{\circ}$ the ${ }^{\circ}$ ion ${ }^{\circ}$ accumulation ${ }^{\circ}$ mode, the ions were trapped in a $163 \mathrm{~mm}$ long quadrupole (inscribed radius of $2.616 \mathrm{~mm}, 6 \mathrm{~mm}$ rod o.d.) operated at $800 \mathrm{KHz}$ frequency and 200 to $600 \mathrm{~V}_{p-p}$ amplitude. The LIT assembly was enclosed in a stainless steel tube (34.8 mm i.d.) maintained at $+3 \mathrm{~V} \mathrm{DC}$ bias. A leak valve (model LV10K; BOC Edwards, Wilmington, MA) with adjustable flow rate (up to $0.1 \mathrm{~L} / \mathrm{s}$ ) provided the pressure adjustment in the LIT region.

The ion packet ejected from the LIT was transferred to the ICR cell using two quadrupole ion guides. The first quadrupole had a length of $133 \mathrm{~mm}$ (inscribed radius of $2.616 \mathrm{~mm}, 6 \mathrm{~mm}$ rod o.d.) and was operated at $800 \mathrm{KHz}$ with $200 \mathrm{~V}_{p-p} \mathrm{RF}$ amplitude and DC bias of $-3 \mathrm{~V}$. The ions passed the first quadrupole guide were transferred into the second quadrupole ion guide through the $1.5 \mathrm{~mm}$ i.d. orifice in the last conductance limit biased to $-4 \mathrm{~V}$. This quadrupole with $347 \mathrm{~mm}$ length (inscribed radius of $2.800 \mathrm{~mm}, 5 \mathrm{~mm}$ rod o.d.) was operated at $800 \mathrm{KHz}(50$ to $150 \mathrm{~V}_{p-p}$ amplitude) and biased to $-20 \mathrm{~V}$ during the ion transfer.

An ensemble of ESI ions that traveled through the last quadrupole was trapped in a $2.54 \mathrm{~cm}$ i.d. cylindrical ICR cell with length-to-diameter aspect ratio of 1 using gated trapping. The ICR cell was mounted at the exit of the last quadrupole electrodes. All ICR cell electrodes were made of gold-plated oxygen-free copper. No buffer gas injection was used in the ICR cell region during ion trapping. Shortly after the ion transfer event, the last quadrupole was switched to ground using two RF switches (CCR-33; Teledyne, Los Angeles, CA) to avoid any pickup noise from the RF generator during the FT-ICR signal detection.

All the quadrupoles were driven by custom-built RF generators with RF amplitude controlled by the datastation software. The distances between the quadrupoles and the conductance limits were the same everywhere and equal to $1 \mathrm{~mm}$.

A commercial barium tungsten dispenser cathode electron gun (model 101101; HeatWave Labs, Watsonville, CA) was used for EI experiments.

\section{Data Station}

The data control system utilized PXI cards from National Instrument installed into a PXI chassis (NI PXI1042). An NI MX-4 interface provided the communication between the PXI chassis and the host computer (Dell PC; 3 GHz Pentium 4 with 2 GB RAM).

A timing card (NI PXI-6602) was used to provide both the internal pulses (triggers) and pulse trains for all other PXI boards with a time accuracy of $12.5 \mathrm{~ns}$ according to the timing defined in the software.

The waveform used for the ion excitation before the detection was generated by an arbitrary waveform generator (NI PXI-5412). It generates signals with a maximum amplitude of $6 \mathrm{~V}_{p-p}$ and 14-bit vertical reso- lution, up to $8 \mathrm{MB}$ long with $100 \mathrm{MS} / \mathrm{s}$ sampling rate. The generated signal further traveled across an RF switch (NI PXI-2590) and was used for dipolar excitation of ions either in the linear ion trap, or the ICR cell. The excitation waveforms were applied across the $50 \Omega$ primary winding of a wide-band RF transformer (North Hills Signal Processing, Syosset, NY). The secondary winding of this transformer had an impedance of $50 \Omega$ with a center tap connected to ground. When a higher amplitude waveform was required, the balun could be replaced with a similar one having higher impedance ratio (up to 1200:50 available).

The excited ions in the ICR cell induced an image charge in the detection circuit, which was amplified by a low-noise 3-stage JFET differential preamplifier. The signal after preamplifier was further amplified and shaped by a commercial voltage amplifier (SR560; Stanford Research, Sunnyvale, CA). To cut off low-frequency noise, a commercial analog filter (SIM965; Stanford Research) was used in the high-pass mode. The amplified and filtered signal was then digitized by a 14-bit resolution analog-to-digital converter (NI PXI-5122). This digitizer can process up to two input signals simultaneously with a maximum sampling rate of $100 \mathrm{MHz}$ and has up to $8 \mathrm{MB}$ memory per channel.

All DC voltages (except the FT-ICR cell's trapping plate voltages) were generated using an analog output board (NI PXI-6723). The board has 13-bit resolution and 32 output channels connected to a home-built voltage distribution unit with the size of a regular PC tower. The unit comprised 12 voltage amplifiers (providing voltages of up to $\pm 300 \mathrm{~V}$ ), a current amplifier for electron gun, and incorporated a power supply from Applied Kilovolts (HPZ series, $\pm 5 \mathrm{KV}$ ) for the ESI source. The outputs from the amplifiers were measured for system control and optimization using a multichannel analog-to-digital board (NI PXI-6220). This board contains 16 analog inputs with 16-bit resolution and up to $250 \mathrm{KS} / \mathrm{s}$ sampling rate. To generate variable voltages for the FT-ICR cell trapping plates with high precision and low noise, a 16-bit analog output board (NI PXI-6733) was used.

In-house developed software ("MassSpecter") controlled all experimental parameters, waveform selection, acquisition of the time-domain signals, and signal processing including common types of apodization, zero-fill, fast Fourier transform, and mass calibration.

\section{Samples and Electrospray Source Operation}

The peptides and proteins, purchased from Sigma (St. Louis, MO) and American Peptides, Inc. (Sunnyvale, CA), were dissolved in a solution containing $49 \%$ water, $49 \%$ methanol, and $2 \%$ acetic acid. The peptide concentration used in the ESI experiments was in the range of 5 to $25 \mu \mathrm{M}$. The solutions were infused into the ESI source at a rate of $1 \mu \mathrm{L} / \mathrm{min}$ using a syringe pump (model 11 Plus; Harvard Apparatus, Holliston, MA). 


\section{Results and Discussion}

The basic characteristics of the constructed FT-ICR analyzer were studied for light ions obtained in EI as well as for the heavy peptide and protein ions from the ESI source. The initial experiments with the EI of the background molecules in the ICR cell revealed a strong self-coherent magnetron motion for large ion populations presented within the FT-ICR cell, similar to that

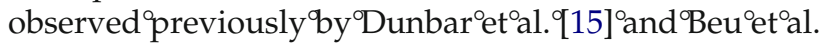

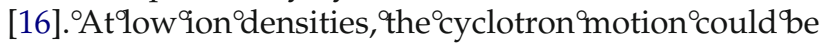
restored and the signals from ions at their reduced cyclotron frequencies observed and measured. No synchronous ion magnetron motion was observed in the ESI mode even at very high ion populations.

Figure $^{\circ} 3 a^{\circ}$ shows $^{\circ}$ the ${ }^{\circ}$ dependence ${ }^{\circ}$ of ${ }^{\circ}$ the ${ }^{\circ}$ magnetron frequency on the trapping voltage measured directly from the ion magnetron motion signal. The rate of the measured shift of $796 \mathrm{~Hz} / \mathrm{V}$ is in good agreement with the predicted value of $720 \mathrm{~Hz} / \mathrm{V}$ calculated using the quadrupolar approximation (near the center of the trap) for the electrostatic potential in the cylindrical ICR trap:

$$
\frac{\Delta v}{\Delta V_{T}}=-\frac{\alpha}{2 \pi d^{2} B}
$$

where $V_{T}$ is the voltage applied to the trapping plates,
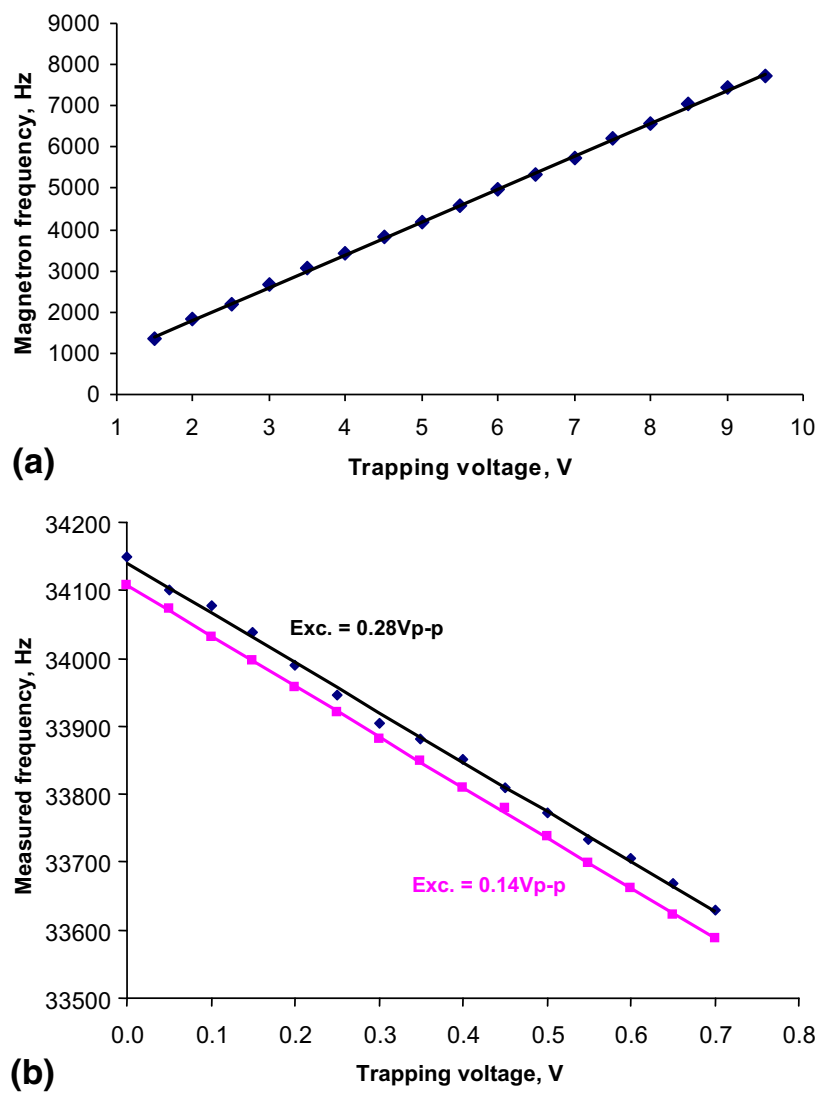

Figure 3. (a) Experimental magnetron frequency shift of the $\mathrm{H}_{3} \mathrm{O}^{+}$ion versus the trapping voltage; (b) experimental ICR frequency shift of the monoisotopic peak of angiotensin I [M + $3 \mathrm{H}]^{3+}$ with the trapping voltage at two different ICR orbital radii. $d$ is the ICR trap diameter, and $\alpha=2.8404$ is the geometry factor for the cylindrical ICR trap with an

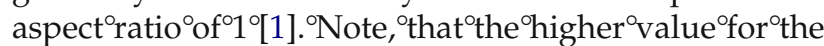
measured magnetron frequency compared with the theoretical one is due to the space charge effect described ${ }^{\circ}$ earlier ${ }^{\circ}$ by $^{\circ}$ Dunbar $^{\circ}$ et $^{\circ}$ al. ${ }^{\circ}[15]$.

The dependence of the observed frequency on the trapping voltage was studied for peptide ions. Peptide ions from the ESI source were dynamically trapped in the ICR cell and cooled down using a $1 \mathrm{~V}$ trapping voltage. After that trapping potentials were decreased to their final values and after a delay of $200 \mathrm{~ms}$, ions were excited using a chirp waveform $(2 \mathrm{~Hz} / \mu$ s rate $)$ followed by the broadband detection $(\mathrm{m} / \mathrm{z}$ from 300 to $1500,512 \mathrm{~K}$ time-domain and a corresponding acquisition $^{\circ}$ time $^{\circ}$ of $\left.^{\circ} 1.04^{\circ} \mathrm{s}\right) .^{\circ}$ Figure $^{\circ} 3 b^{\circ}$ contains $^{\circ}$ plots $^{\circ}$ of ${ }^{\circ}$ the observed frequency shift for the monoisotopic peak of angiotensin $\mathrm{I}[\mathrm{M}+3 \mathrm{H}]^{3+}$ versus trapping voltage at two different ICR orbital radii. The observed frequency shifts were $742 \mathrm{~Hz} / \mathrm{V}$ for the lower orbital radius and $733 \mathrm{~Hz} / \mathrm{V}$ for the higher radius.

\section{Mass Resolving Power}

Initial experiments that utilized electron impact ionization yielded a mass resolving power (full-width at half-maximum, FWHM) of $\sim 80,000$ for the $\mathrm{H}_{3} \mathrm{O}^{+}$ion generated from the background water molecules (mass spectrum $^{\circ}$ is $^{\circ}$ shown $^{\circ}$ in $^{\circ}$ Figure $\left.^{\circ} 4 a\right)^{\circ}$ at $^{\circ}$ the ${ }^{\circ}$ measured reduced cyclotron frequency of $805 \mathrm{kHz}$ with a transient duration of $250 \mathrm{~ms}$. Importantly, the major limitation in the EI mode for the mass resolving power was coming from the vacuum conditions, worsened due to heat from the dispenser cathode. Particularly, the mass spectrum $^{\circ}$ shown $^{\circ}$ in $^{\circ}{ }^{\circ}$ igure $4 a^{\circ}$ has ${ }^{\circ}$ been ${ }^{\circ}$ measured ${ }^{\circ} a^{\circ}$ the relatively low vacuum of $\sim 10^{-7}$ torr. The reported mass resolving power is not a limit for the PM-based FT-ICR instruments and can be significantly enhanced in the future, ${ }^{\text {thus }}$ matching ${ }^{9}$ the ${ }^{\circ}$ results ${ }^{\circ}$ obtained ${ }^{\circ}$ earlier $\left[4,{ }^{\circ}\right.$,17].

For the ions produced by ESI, a mass resolving power of up to 25,000 (FWHM) was achieved with isotopically ${ }^{\circ}$ resolved ${ }^{\circ}$ mass $^{\circ}$ spectra $^{\circ}$ of $^{\circ}$ peptides. ${ }^{\circ}$ Figure $4 \mathrm{~b}^{\circ}$ shows $^{\circ}$ the $^{\circ} \mathrm{ESI}^{\circ}$ mass $^{\circ}$ spectrum ${ }^{\circ}$ of $^{\circ}$ an $^{\circ}$ equimolar mixture of bradykinin and angiotensin II. The spectrum was obtained in a single scan using a $0.3 \mathrm{~V}_{\mathrm{p}-\mathrm{p}}$ chirp excitation $(\mathrm{m} / \mathrm{z}$ range 300 to $1500,2 \mathrm{~Hz} / \mu \mathrm{s})$ and broadband detection with $512 \mathrm{~K}$ data points $(1.04 \mathrm{~s}$ of detection time).

A well-known effect often leading to the pronounced broadening of the observed FT-ICR mass spectral peak

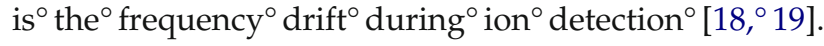
Figure ${ }^{\circ} 5^{\circ}$ shows $^{\circ}$ the ${ }^{\circ} \mathrm{drift}^{\circ}{ }^{\circ}{ }^{\circ}$ the ${ }^{\circ}$ observed ${ }^{\circ}$ frequency ${ }^{\circ}$ for the monoisotopic peak of bradykinin $[\mathrm{M}+2 \mathrm{H}]^{2+}$ ("nominal" frequency for the peak is $27,870 \mathrm{~Hz}$ ) over the detection period. The frequency drift was quantified by the Fourier transformation of each of five consecutive segments of the time-domain ICR signal (total duration of $1.04 \mathrm{~s}$ with $512 \mathrm{~K}$ data points). Contrary to the commonly observed negative trends in the fre- 

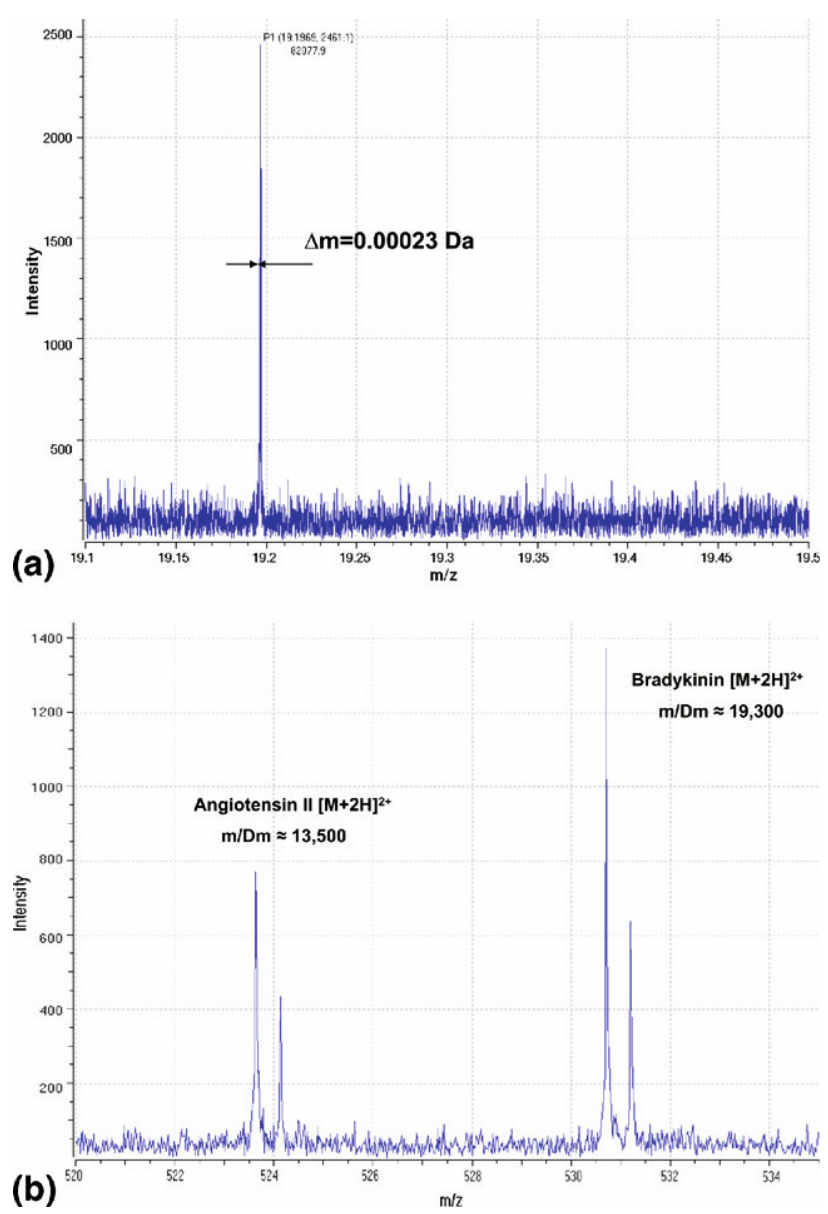

Figure 4. (a) EI mass spectrum of $\mathrm{H}_{3} \mathrm{O}^{+}$ions resulting from the proton transfer reaction between the background water molecules; (b) ESI mass spectrum of an equimolar mixture of bradykinin and angiotensin II.

quency ${ }^{\circ} \mathrm{drift}^{\circ}\left[18,{ }^{\circ} 20\right],{ }^{\circ} \mathrm{obtained}^{\circ} \mathrm{data}^{\circ} \mathrm{show}^{\circ} \mathrm{a}^{\circ}$ continuous positive frequency drift of $\sim 0.6 \mathrm{~Hz} / \mathrm{s}$. This positive frequency shift with time can be explained through the mechanism ${ }^{\circ}$ suggested ${ }^{\circ}$ by $^{\circ} \mathrm{Guan}^{\circ} \mathrm{et}^{\circ}{ }^{\circ} \mathrm{l}^{\circ} \cdot{ }^{\circ}[18]^{\circ} \cdot{ }^{\circ}$ Ions ${ }^{\circ}$ excited to a large cyclotron orbit collide with the residual gas molecules and move to the center of the ICR cell thus decreasing their amplitudes of axial oscillations. Since the axial magnetic field profile of the permanent magnet used has a very pronounced maximum at the center

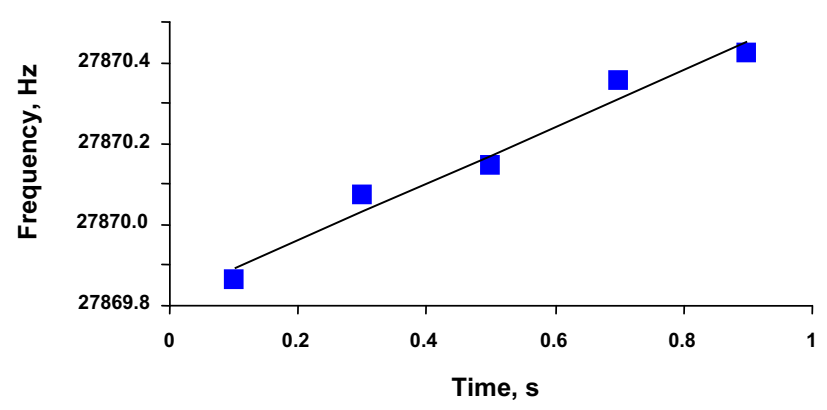

Figure 5. Dependence of the drift in the observed frequency of the monoisotopic peak of bradykinin $(2+$ charge state) on the acquisition time.
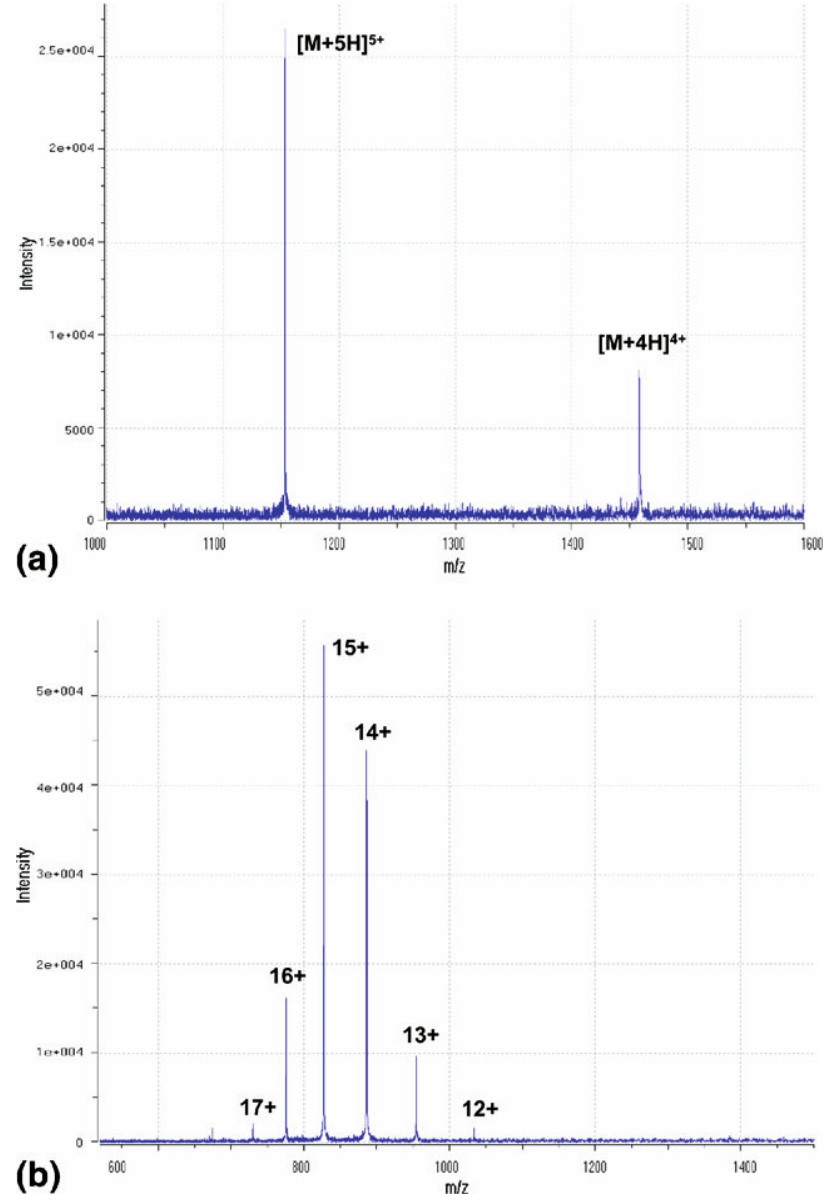

Figure 6. ESI mass spectra obtained for (a) bovine insulin (zoomed in the 1000 to $1500 \mathrm{~m} / \mathrm{z}$ range) and (b) bovine heart cytochrome $c$.

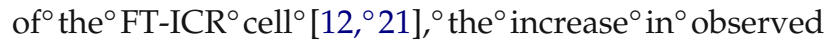
cyclotron frequency with time due to the increase in magnetic field prevails over the decrease in the frequency caused by the increasing ion density. We plan to study all the factors affecting the frequency drift in future work to attempt further improvement of the resolution.

\section{Upper Mass Limit}

One of the expected limitations of permanent magnet FT-ICR mass spectrometry, resulting from the lower magnetic field and the small size ICR cell, would be a reduced ion mass-to-charge ratio range. The so-called "critical" mass limit imposed by the three-dimensional axial quadrupolar trapping potential is usually defined by $^{\circ}$ the ${ }^{\circ}$ following ${ }^{\circ}$ expression ${ }^{\circ}[1]$ :

$$
m_{\text {upper }}=\frac{q B^{2} d^{2}}{4 \alpha V_{T}}
$$

For typical experimental parameters used in this work (0.97 tesla magnetic field, $2.54 \mathrm{~cm}$ FT-ICR cell diameter, 
$0.05 \mathrm{~V}$ trapping voltage, and $\alpha=2.8404$ ), the expected "critical" $m / z$ is $\sim 103,000$ that is well above the $\mathrm{m} / \mathrm{z}$ range in the most applications of biological mass spectrometry.

Although our experiments were not targeted specifically toward investigating a high $\mathrm{m} / \mathrm{z}$ range, the obtained results have demonstrated that the ion masses with ${ }^{\circ} \mathrm{m} / \mathrm{z}$ of ${ }^{\circ}$ up $^{\circ}$ to $^{\circ} 1500^{\circ} \mathrm{Can}^{\circ}$ be $^{\circ}$ measured $^{\circ}$ ( see $^{\circ}$ Figure $^{\circ} 6 \mathrm{a}$ ). Typically, the ESI source delivers multiple-charged peptide ions over $\mathrm{m} / \mathrm{z}$ range from 300 to 1500 . Therefore with ESI of even very large proteins, their $\mathrm{m} / \mathrm{z}$ window fits the mass range of our instrument and thus the mass analysis ${ }^{\circ}$ of ${ }^{\circ}$ roteins is ${ }^{\circ}$ quite ${ }^{\circ}$ easible. Figure $6 b^{\circ}$ shows ${ }^{\circ}$ an ESI PM-FTICR mass spectrum of bovine cytochrome $c$ ions (MW $\sim 12.4 \mathrm{kDa}$ ).

\section{Mass Measurement Accuracy}

The mass accuracy is a key performance characteristic of a modern mass spectrometer. In this work, the mass measurement accuracy was determined from the isotopically resolved ESI mass spectra of a standard peptide mixture. The spectra were acquired using a broadband detection mode $\left(0.05 \mathrm{~V}\right.$ trapping voltage, $0.3 \mathrm{~V}_{p-p}$ chirp excitation, $m / z$ range of 300 to $1500,1.04 \mathrm{~s}$ data acquisition time, $512 \mathrm{~K}$ data points). The $\mathrm{m} / \mathrm{z}$ ratios were determined from the measured frequencies corresponding to the monoisotopic peaks using the two-term calibration: ${ }^{\circ} \mathrm{m} / \mathrm{z}={ }^{\circ} \mathrm{a} / \mathrm{f}^{\circ}+{ }^{\circ} \mathrm{b} / \mathrm{f}^{{ }^{\circ}}[22] .^{\circ}$ Figure ${ }^{\circ} 7 \mathrm{a}^{\circ}$ shows ${ }^{\circ}$ the mass spectrum of the calibration mixture containing five peptides: bradykinin ( $2+$ charge state), angiotensin I $(2+$ and $3+$ charge states), Substance P $(2+$ and $3+$ charge states), leucine enkephalin (1+ charge state) and $\alpha$-endorphin ( $2+$ charge state). The average mass measurement accuracy based on the mean standard deviation of the measured masses from the exact masses was $10 \mathrm{ppm}$. The discrepancies between the measured and theoretical ${ }^{\circ}$ masses $^{\circ}$ are $^{\circ}$ also $^{\circ}$ given $^{\circ}$ in $^{\circ}$ Figure $^{\circ} 7 \mathrm{a}^{\circ}$ for monoisotopic peptide peaks. The achieved mass accuracy is comparable with that of the commercial mass spectrometers. For example, mass measurement accuracy of 20 to $30 \mathrm{ppm}$ is a zero-space charge limit of LTQ MS $^{\circ}$ instruments ${ }^{\circ}$ [23].

With a large amount of ions accumulated in the FT-ICR cell, the ions with close mass-to-charge ratios become "locked" in the same frequency, and no isotopic patterns are observed (this phenomenon is known as "coalescence" $\left.{ }^{\circ}\left[24,{ }^{\circ} 25\right]\right) .^{\circ}$ For $^{\circ}$ the ${ }^{\circ}$ developed ${ }^{\circ}$ instrument, we call this mode of operation as the low-resolution mode. The specific feature of this mode is the high dynamic range (up to 10,000) with the trade-off of having isotopically unresolved mass spectra of the peptide ions. Importantly, even for such a low resolution mode, the mass measurement accuracy was in the range ${ }^{\circ}$ of $50^{\circ}$ to $^{\circ} 150^{\circ} \mathrm{ppm}$. ${ }^{\circ}$ Figure ${ }^{\circ} 7 \mathrm{~b}^{\circ}$ shows $^{\circ}$ an $^{\circ}$ example ${ }^{\circ}$ of mass spectrum of the peptide mixture containing angiotensin I, bradykinin, Substance P, and $\alpha$-endorphin acquired in this mode of operation. Another useful feature of this mode of operation is that the mass
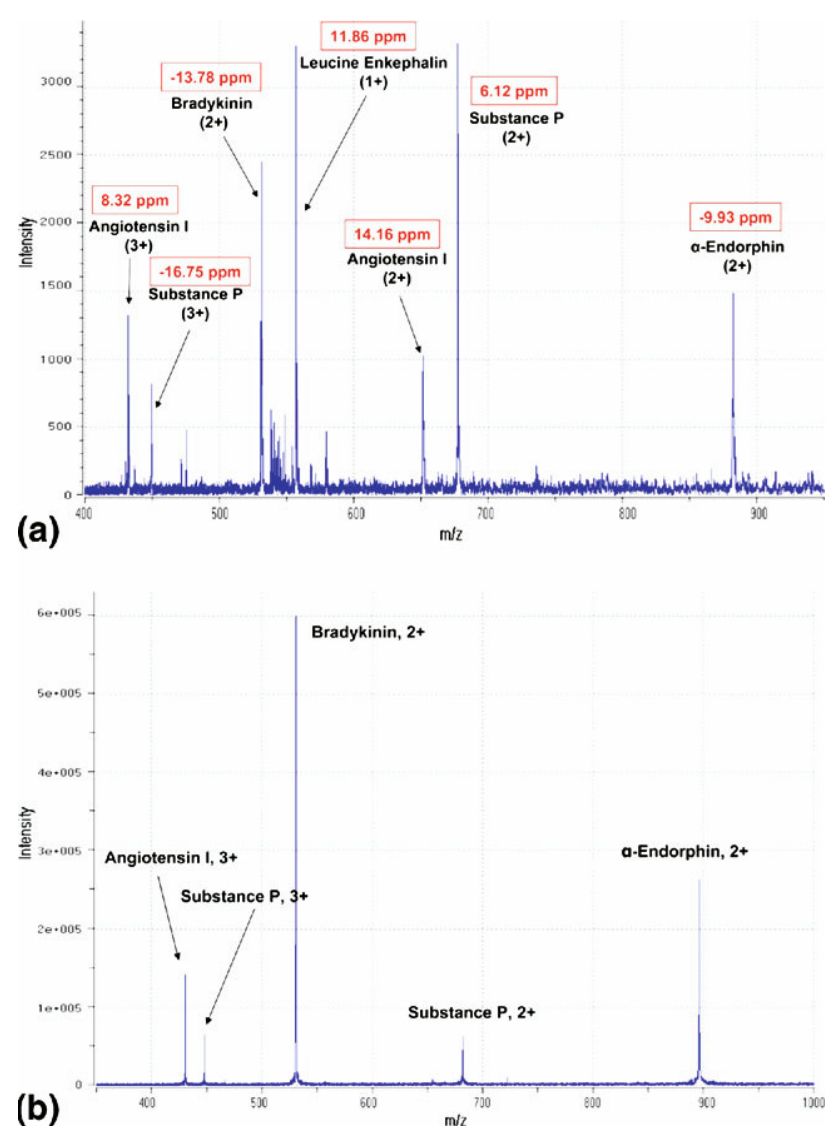

Figure 7. ESI mass spectrum of (a) a five peptides mixture under the reduced space charge conditions and (b) a four peptides mixture obtained under the excessive space charge conditions.

spectra can be acquired using short experimental sequence of less then $0.3 \mathrm{~s}$ per spectrum (with the acquisition period down to $50 \mathrm{~ms}$ ). This feature will be helpful in high-throughput LC-MS applications or as a pre-scan ${ }^{\circ}$ for $^{\circ}$ automatic ${ }^{\circ}$ gain $^{\circ} \operatorname{control}^{\circ}(\mathrm{AGC})^{\circ}[26]$.

\section{Conclusions}

A new permanent magnet hybrid FT-ICR mass spectrometer with an electrospray ionization source has been constructed and its initial performance has been evaluated. A mass resolving power (FWHM) of up to 80,000 in the electron ionization mode and 25,000 in the ESI mode was demonstrated. Mass measurement accuracy at a low-ppm level in a mass range of up to 1200 $\mathrm{m} / \mathrm{z}$ has been routinely achieved for the complex peptide mixtures with the fully resolved isotopic patterns. Further improvements in the instrument performance are expected after the installation of a new permanent magnet with higher field (1.26 tesla) and larger internal bore $(5 \mathrm{~cm})$. Future efforts will also be focused on the implementation of the electron-capture dissociation (ECD) technique, coupling the instrument to a liquid chromatography system, as well as further software and data station development. 


\section{Acknowledgments}

This work was supported in part by a SBIR grant from the National Institute of Health (2R44RR020288-02) to Science and Engineering Services Inc. (Columbia, MD), Russian Basic Science Foundation (grants $06-08-08,085$ and $06-04-49,632$ ) as well as the U.S. Civilian Research and Developments Foundation (grant RUE1-000588-MO-05). The authors thank Dr. Alexander Spasski, Sang M. Lee, and Howard Nghiem for the electronics development, Kevin Felber and Vladimir Driven for their aid in engineering design and mechanical assembly.

\section{References}

1. Marshall, A. G.; Hendrickson, C. L.; Jackson, G. S. Fourier Transform Ion Cyclotron Resonance Mass Spectrometry: A Primer. Mass Spectrom. Rev. 1998, 17(1), 1-35.

2. Bogdanov, B.; Smith, R. D. Proteomics by FTICR Mass Spectrometry: Top Down and Bottom Up. Mass Spectrom. Rev. 2005, 24(2), 168-200.

3. Zhang, L. K.; Rempel, D. L.; Pramanik, B. N.; Gross, M. L. Accurate Mass Measurements by Fourier Transform Mass Spectrometry. Mass Spectrom. Rev. 2005, 24, 286-309.

4. Gorshkov, M. V.; Udseth, H. R.; Anderson, G. A.; Smith, R. D. High Performance Electrospray Ionization Fourier Transform Ion Cyclotron Resonance Mass Spectrometry at Low Magnetic Field. Eur. J. Mass Spectrom. 2002, 8, 169-176.

5. Wu, Q.; Anderson, G. A.; Udseth, H. R.; Sherma, M. G.; Van Orden, S. Chen, R.; Hofstadler, S. A.; Gorshkov, M. V.; Mitchell, D. W.; Rockwood, A. L.; Smith, R. D. A High Performance Low Magnetic Field Internal Electrospray Ionization-Fourier Transform Ion Cyclotron Resonance Mass Spectrometer. J. Am. Soc. Mass Spectrom. 1996, 7, 915-922.

6. Dietrich, D. D.; Keville, R. F. Electron Source for a Mini-Ion Trap Mass Spectrometer; U.S. Patent 5,477,046; 1995

7. Zeller, L. C.; Kennady, J. M.; Kenttamaa, H.; Campana, J. E. Characterization of a Small FT-ICR Mass Spectrometer Based on a Permanent Magnet. Anal. Chem. 1993, 65, 2116-2118.

8. Jones, J. J.; Wilkins, C. L. Bacterial Pyrolysis Products Analyzed Using a Portable High Resolution 1 tesla Fourier Transform Mass Spectrometer. Proceedings of the 52nd ASMS Conference on Mass Spectrometry and Allied Topics; Nashville, TN, 2004

9. Rimkus, W. V.; Davis, D. V.; Gallaher, K. Learn FTMS Fundamentals and Quantitation on an Inexpensive Rugged Machine-Save Your High Powered FTMS for the Experienced User. Proceedings of the 53rd ASMS Conference on Mass Spectrometry and Allied Topics; San Antonio, TX, 2005.

10. Mauclaire, G.; Lemaire, J.; Boissel, P.; Bellec, G.; Heninger, M. MICRA: A Compact Permanent Magnet Fourier Transform Ion Cyclotron Resonance Mass Spectrometer. Eur. I. Mass Spectrom. 2004, 10(2), 155-162.

11. Gorshkov, M. V. Permanent Magnet Structure with Axial Access for Spectroscopy Applications; U.S. Patent Application 20,060,232,368; 2005.
12. Tarasova, I. A.; Tolmachev, D. A.; Vilkov, A. N.; Doroshenko, V. M.; Gorshkov, M. V. Permanent Magnet Assembly for Ion Cyclotron Resonance Mass Spectrometer with Atmospheric Pressure Ionization Sources. Mass Spectrometriya 2006, 3(2), 89-100.

13. Moskowitz, L. R. Permanent Magnet Design and Application Handbook; Krieger Publishing Co.: Malabar, FL, 1995, pp. 548-578.

14. Gamage, C. M.; Misharin, A. S. Vilkov, A. N.; Gorshkov, M. V. Doroshenko, V. M. ECD and CID of Peptide Ions in a Hybrid Permanent Magnet FT-ICR Mass Spectrometer. Proceedings of the 55th ASMS Conference on Mass Spectrometry and Allied Topics; Indianapolis, IN, 2007.

15. Dunbar, R. C.; Chen, J. H.; Hays, J. D. Magnetron Motion of Ions in the Cubical ICR Cell. Int. J. Mass Spectrom. Ion Processes 1984, 57, 39-56.

16. Beu, S. C.; Laude, D. A. Radial Ion Transport Due to Resistive-Wall Destabilization in Fourier Transform Mass Spectrometry. Int. J. Mass Spectrom. Ion Processes 1991, 108, 255-268.

17. White, R. L.; Ledford, E. B., Jr.; Ghaderi, S.; Wilkins, C. L.; Gross, M. L. Resolution and Signal-to-Noise in Fourier Transform Mass Spectrometry. Anal. Chem. 1980, 52(9), 1525-1527.

18. Guan, S.; Wahl, M. C.; Marshall, A. G. Elimination of Frequency Drift from Fourier Transform Ion Cyclotron Resonance Mass Spectra by Digital Quadrature Heterodyning: Ultrahigh Mass Resolving Power for Laser-Desorbed Molecules. Anal. Chem. 1993, 65(24), 3647-3653.

19. Bruce, J. E.; Anderson, G. A.; Hofstadler, S. A.; Winger, B. E.; Smith., R. D. Time-Base Modulation for the Correction of Cyclotron Frequency Shifts Observed in Long-Lived Transients from Fourier-transform IonCyclotron-Resonance Mass Spectrometry of Electrosprayed Biopolymers. Rapid Commun. Mass Spectrom. 1993, 7, 700-703.

20. Guan, S.; Wahl, M. C.; Wood, T. D.; Marshall, A. G. Enhanced Mass Resolving Power, Sensitivity, and Selectivity in Laser Desorption Fourier Transform Ion Cyclotron Resonance Mass Spectrometry by Ion Axialization and Cooling. Anal. Chem. 1993, 65(13), 1753-1757.

21. Vilkov, A. N.; Gamage, C.; Oktem, B.; Shanbhag, S.; Doroshenko, V. M Tarasova, I. A.; Tolmachev, D. A.; Gorshkov, M. V. Atmospheric Pressure Ionization Permanent Magnet FTICR Mass Spectrometer: A Way to High Performance Mass Spectrometry in a Bench-Top Size. Proceedings of the 54th ASMS Conference on Mass Spectrometry and Allied Topics; Seattle, WA, 2006

22. Ledford, E. B., Jr.; Rempel, D. L.; Gross, M. L. Space Charge Effects in Fourier Transform Mass Spectrometry. Mass calibration. Anal. Chem. 1984, 56(14), 2744-2748.

23. Gorshkov, M. V.; Zubarev, R. A. Linear Ion Trap Mass Spectrometer LTQ: Testing the Limits in Mass Accuracy and Resolution. Proceedings of the 53rd ASMS Conference on Mass Spectrometry and Allied Topics; San Antonio, TX, 2005.

24. Mitchell, D. W.; Smith, R. D. Cyclotron Motion of Two Coulombically Interacting Ion Clouds with Implications to Fourier-Transform Ion Cyclotron Resonance Mass Spectrometry. Phys. Rev. E 1995, 52(4), 4366-4386.

25. Peurrung, A. J.; Kouzes, R. T. Long-Term Coherence of the Cyclotron Mode in a Trapped Ion Cloud. Phys. Rev. E 1994, 49(5), 4362-4368

26. Belov, M. E.; Zhang, R.; Strittmatter, E. F.; Prior, D. C.; Tang, K.; Smith, R. D. Automated Gain Control and Internal Calibration with External Ion Accumulation Capillary Liquid Chromatography-Electrospray Ionization Fourier Transform Ion Cyclotron Resonance. Anal. Chem. 2003, 75(16), 4195-4205. 